\title{
Likability as a function of age, sex, and personality description
}

\author{
JULIET POPPER SHAFFER \\ University of Kansas, Lawrence, Kansas 66044
}

\begin{abstract}
Previous research has indicated that college students make more polarized likability ratings of college-age stimulus persons of the opposite sex than of those of the same sex, that is, opposite-sex stimulus persons described positively yield higher ratings, and those described negatively yield lower ratings, than same-sex stimulus persons. The two further experiments described here provide additional information about this effect, which is designated the polarization effect. In Experiment 1, subjects asked to make ratings from the point of view of the opposite sex were successful in producing the appropriate polarization effect, demonstrating that the point of view enters into the rating for the subject. In Experiment 2, age of the stimulus person was introduced as an additional variable. The polarization effect occurred only when the stimulus person was similar in age to the subject, and older stimulus persons of both sexes produced less polarized ratings than those nearer the subjects' ages.
\end{abstract}

A series of studies of personality impression formation have demonstrated that, when college students rate likability of hypothetical stimulus persons their age described by personality-trait adjectives, their ratings are more polarized for stimulus persons of the opposite sex; that is, a stimulus person of the opposite sex is rated more likable if the description is positive, and less likable if it is negative, than a stimulus person of the same sex (Combest, Kasten, \& Shaffer, 1973; Shaffer, 1975). This paper reports two experiments designed to investigate further aspects of this phenomenon, which will be referred to as the polarization effect.

Since raters in the previous experiments were asked how much they would like the stimulus persons described, rather than how likable such stimulus persons would be to people in general, their ratings might have been influenced by considering the stimulus persons from the viewpoint of their own sex. For example, they might have been thinking in terms of more intimate potential relationships when making ratings for stimulus persons of the opposite as compared with those of the same sex, and the personality traits might therefore have had more impact on opposite-sex ratings. Experiment 1 was designed to test the effect of the reference group. Subjects rated likability of stimulus persons of their own age of both sexes described by either two, three, or six like-valued adjectives, but one group rated how likable they thought the stimulus persons would be to women in general, while the other group rated how likable they thought the stimulus persons would be to men in general. If the relationship between the rater and the stimulus person were a determining factor for the sub-

The author wishes to thank Jeanne Hierl, Carol Lollman, and Peggy Hineline for assistance in conducting the experiments. ject, there should be greater polarization in rating subjects of the sex opposite to that of the assumed reference group, that is, to women in general or men in general, depending upon the instructions given the subject and independent of the subject's own sex.

Regardless of whether the polarization effect is a function of the sex of the subject or of the reference group, one might also raise the issue of whether or not it is a function of the degree of similarity of the rater to the stimulus person. Since polarization is greater when rating likability of stimulus persons unlike oneself as far as sex is concerned, one might expect still greater polarization in rating likability of stimulus persons who differ from oneself in ways other than sex. Specifically, since previous experiments dealt with stimulus persons of the subjects' own age, one might expect still greater polarization when the age of the stimulus person was farther from the age of the subject, if similarity between stimulus person and rater were involved. On the other hand, if the potential of an especially strong relationship with a person of one's own age and the opposite sex leads to greater polarization in rating such a person, one would expect less polarization in ratings of stimulus persons of other ages: both less polarization effect due to sex of subjects, since the sex difference would not have the same implications for a different relationship in persons of a very different age group, and perhaps less polarization even than for like-age stimulus persons of the same sex, since a still more remote relationship than that to like-sex peers might be expected.

Experiment 2 was designed to provide evidence on the magnitude of polarization in relation to both sex and age of the stimulus persons. College students rated likability to themselves of stimulus persons described by either two or four like-valued adjectives. For each 
stimulus person there was both a sex designation and an age designation. The ages used were "early 20 s," "late 30 s," and "early 50 s."

\section{EXPERIMENT 1}

\section{Method}

Subjects. The subjects were 160 college students, 80 women and 80 men, fulfilling a research participation requirement in introductory psychology.

Materials and procedure. Each subject received 12 practice trials followed by 96 main trials. On each trial, the stimulus person was a woman or man described by acquaintances as having the designated personality traits. The adjectives used in constructing descriptions were from four value ranges as determined by Anderson's (1968) 6-point ratings: extremely positive (ratings from 4.78 to 5.29 ), moderately positive (ratings from 3.34 to 4.11 ), moderately negative (ratings from 2.09 to 2.60 ), and extremely negative (ratings from .43 to 1.09 ).

Practice trials were constructed from four sets of six adjectives each, two extremely positive adjective sets (EP1 and EP2) and two extremely negative adjective sets (EN1 and EN2). Three adjective combinations were constructed from each set, containing one, three, and six adjectives, respectively. Subjects given List Combination 1 rated a female stimulus person with EP1 and EN1 stimuli and a male stimulus person with EP2 and EN2 stimuli; subjects given List Combination 2 rated a male stimulus person with EP1 and EN1 stimuli and a female stimulus person with EP2 and EN2 stimuli.

Main trials were constructed from four 12-adjective sets, one extremely positive adjective set (EP), one extremely negative adjective set (EN), one moderately positive adjective set (MP), and one moderately negative adjective set (MN). Two groups of 48 adjective combinations each were constructed by using combinations of two, three, and six adjectives. Each combination consisted of adjectives from within a single set (thus, likevalued adjectives), and each adjective appeared once in a twoadjective, once in a three-adjective, and once in a six-adjective combination in each group. No specific combination of adjectives was used more than once in the 96 trials. Subjects given List Combination 1 rated female stimulus persons on the first group of combinations and male stimulus persons on the second; subjects given List Combination 2 rated male stimulus persons on the first group of combinations and female stimulus persons on the second.

Adjective combinations were typed six to a page, in a random ordering of the 12 practice stimuli (first 2 pages) followed by a random ordering of the 96 main stimuli (next 16 pages). The first 2 pages were randomly ordered for each subject, and were followed by the next 16 pages randomly ordered for each subject.

Design. The experiment was carried out in an equal-N mixed analysis of variance design, with three between-subject factors: sex of subject, list combination, and women or men as reference group. There were four within-subject factors: sex of stimulus person, positivity or negativity of the adjectives, moderate or extreme values of adjectives, and number of adjectives.

\section{Results}

As predicted, when subjects were rating stimulus persons as they thought persons of their (the subjects') own sex would rate them, the polarization effect occurred: Ratings of stimulus persons of the opposite sex were more polarized than ratings of stimulus persons of the same sex $[F(1,76)=31.55, p<.001]$. Furthermore, when averaged over positive and negative adjectives, the mean ratings were not significantly different for male and female subjects or for male and female stimulus persons, nor was there a significant interaction of Sex of Subject by Sex of Stimulus Person $[F(1,76)=$ $.37, .001$, and 1.12 , respectively] .

On the other hand, when subjects were rating stimulus persons as they thought they would be rated by persons of the sex opposite to that of the subject, ratings of stimulus persons of the same sex as the subject were more polarized than ratings of stimulus persons of the opposite sex $[\mathrm{F}(1,76)=30.98, \mathrm{p}<.001]$; that is, subjects reacted in a way appropriate to the opposite sex. Thus, the polarization effect is clearly a function of the frame of reference of the subject in making the rating. Mean polarization scores under the different conditions are given in Table 1.

\section{EXPERIMENT 2}

\section{Method}

Subjects. The subjects were 84 college students, 42 male and 42 female, fulfilling a research participation requirement in introductory psychology. Their ages ranged from 17 to 28 years, but only $2 \%$ were over 25 years and $93 \%$ were 21 years or younger.

Materials and procedure. As in Experiment 1, each subject received 12 practice trials followed by 96 main trials. On each trial the stimulus person was described as a woman or man in her/his early $20 \mathrm{~s}$, late $30 \mathrm{~s}$, or early $50 \mathrm{~s}$, and described by acquaintances as having the designated personality traits. The age designations will be referred to as 20,30 , and 50 . The adjectives used in constructing descriptions were a subset of those used in Experiment 1. Adjective combinations were constructed in a similar manner, except that each combination contained either two or four like-valued adjectives. Within each evaluative range, on the main trials, each subject rated two twoadjective and two four-adjective combinations for each of the six age-sex designations of the stimulus persons; the specific assignments of adjective combinations to age-sex designations were counterbalanced across subjects.

The arrangement of adjectives on pages and the order in which they were given was determined in the same manner as in Experiment 1.

Design. The experiment was carried out in an equal-N mixed analysis of variance design, with three between-subject factors: sex of subject, list-sex combination, and list-age combination. There were five within-subject factors: sex of stimulus person, age of stimulus person, positivity or negativity of adjectives, moderate or extreme values of adjectives, and number of adjectives.

\section{Results}

The effects of greatest interest for shedding light on

Table 1

Mean Polarization Scores in Experiment 1 for Stimulus Persons of the Same and the Opposite Sex

\begin{tabular}{ccc} 
& \multicolumn{2}{c}{ Sex of Stimulus Person } \\
\cline { 2 - 3 } Reference Group & $\begin{array}{c}\text { Same as } \\
\text { Subject }\end{array}$ & $\begin{array}{c}\text { Opposite to } \\
\text { Subject }\end{array}$ \\
\hline Like Sex & 28.43 & 31.40 \\
Opposite Sex & 32.51 & 30.09 \\
\hline
\end{tabular}

Note-Mean polarization score equals mean rating on positive adjectives minus mean rating on negative adjectives. 
the significance of the polarization effect are the magnitude of polarization and the magnitude of the polarization effect (differential same-sex/opposite-sex polarization) as a function of age. Polarization, measured by the difference between the mean rating for positive adjectives and the mean rating for negative adjectives, interacted significantly with age $[\mathrm{F}(2,144)=7.45$, $\mathrm{p}<.001]$. The mean polarization scores, from the youngest to the oldest stimulus persons, were 31.19 , 29.93 , and 29.35. The linear component of the trend was significant $[\mathrm{F}(1,72)=11.84, \mathrm{p}<.001]$, while the quadratic was not $[\mathrm{F}(1,72)=.82]$. Thus, polarization decreased as the age of the stimulus person became more remote from the age of the subject, at least for the ages of subjects and stimulus persons in the experiment.

The polarization effect, that is, the tendency to rate opposite-sex stimulus persons in a more polarized manner, was not significant $[F(1,72)=.97]$, but its interaction with Age was of borderline significance $[F(2,144)=$ $2.96, p=.055]$. The mean polarization scores by sex (same as or opposite to subject) and age of stimulus person are shown in Figure 1. The polarization effect (opposite-sex polarization score minus same-sex polarization score) decreased from the youngest to the oldest age, even reversing slightly at the oldest age. The linear component of the trend was significant $[F(1,72)=5.20$, $\mathrm{p}=.026]$, while the quadratic component was not $[F(1,72)=.003]$. Thus, the polarization effect also decreased as the age of the stimulus person became more remote from the age of the subject. Tests of the significance of the polarization effect at each age level showed that the effect was significant at the youngest age $[F(1,72)=4.32, p=.041]$ but was not significant at either of the older ages $[\mathrm{F}(1,72)=.40$ and 1.57 , respectively].

\section{DISCUSSION}

Experiment 1 provided clear evidence that the polarization effect, that is, the tendency to give more polarized likability ratings for the opposite than for the same sex, is a function of the subjects' reference group: The effect was highly significant when the subjects adopted the point of view of their own sex and that of the opposite sex, but was a function of the sex of the reference group (i.e., the group from whose point of view the subject was rating) rather than the sex of the subject. Experiment 2 provided evidence that both the amount of polarization and the size of the polarization effect decreased with age of the stimulus person, for subjects who were younger than the stimulus persons, and thus decreased as the stimulus person became more dissimilar in age to the subject. The effect at the youngest stimulus person age, although significant, was somewhat weaker than has been obtained when subjects rated

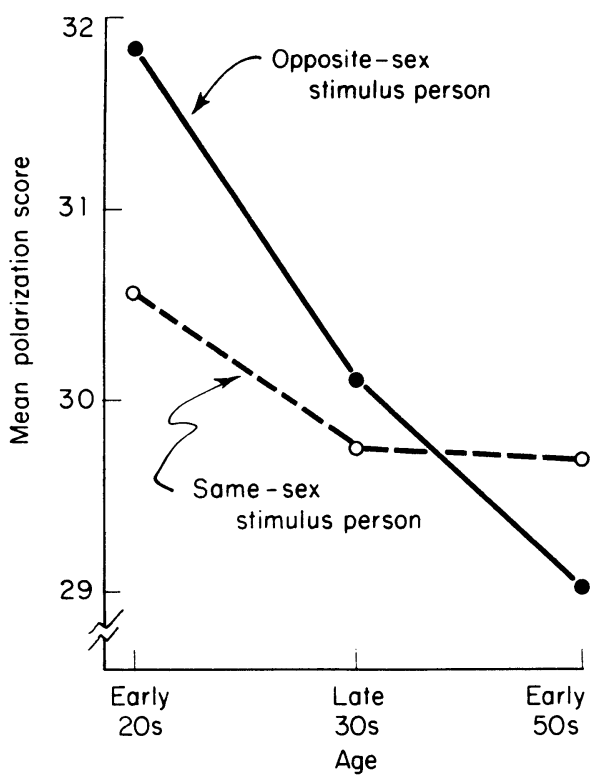

Figure 1. Mean polarization score as a function of sex (same or opposite) and age of stimulus person.

stimulus persons of their own age, but even the youngest stimulus persons (in their "early 20s") were slightly older than most of the subjects, $93 \%$ of whom were 21 years or younger.

Taken together, the results do not support the hypothesis that the degree of polarization can be accounted for by the similarity of the subject and the stimulus person, since at the same age, stimulus persons of the opposite sex, that is, more dissimilar stimulus persons, receive more polarized likability ratings, while as age varies, older stimulus persons, more dissimilar to the subjects, receive less polarized likability ratings. Rather, the results are consistent with the supposition that anticipation of greater or more intense personal interaction may result in greater polarization of likability ratings, or, in other words, in a greater influence of the descriptive adjectives on the ratings. A direct test of this hypothesis would be desirable.

\section{REFERENCES}

ANDERSon, N. H. Likableness ratings of 555 personality-trait words. Journal of Personality and Social Psychology, 1968, 9, 272-279.

Combest, W., Kasten, K., \& Shaffer, J. P. The relationship between personality impression formation and sex: An application of information integration theory. Bulletin of the Psychonomic Society, 1973, 1, 2-4.

SHAFFER, J. P. Personality impression formation and sex: The polarization effect. Bulletin of the Psychonomic Society, 1975, 6, 661-664.

(Received for publication January 12, 1977.) 